\title{
Meteorological Factors and Forest Fires in the United States.
}

FOREST fires have long been a source of damage and loss in North America, and for many years the U.S. Department of Agriculture, by the aid of the Forest Service and the Weather Bureau, has sought, so far as possible, to mitigate the amount of havoc by fire control. Necessarily immense difficulties harass the work in many ways, but without doubt the unceasing care and activity of those engaged is telling in its results. A prime feature in the discussion is the forecasting of fire-weather with the object of avoiding the fires or competing with them when necessary. The U.S. Monthly Weather Review for the past two years contains many varied articles on the subject, written from different points of view. Only the merest reference can be made to them here in the space available. Occasional articles have appeared for at least ten or twelve years connecting the forest fires with lightning, but it is only in the last two years- 1922 and 1923 - that the communications have become so frequent and widespread. In 1923 there were at least I2 communications, 7 of which occur in the November number. It is almost invidious to single out those by special authors-all of which are either attached to the Forest Service or the Weather Bureau.

In the Monthly Weather Review for March 192I, Mr. E. N. Munns of the Californian Forest Service endeavours to correlate evaporation and forest fires, associating evaporation with temperature, humidity, and wind. In the issue for February r922, "Climate and Forest Fires in Montana and Northern Idaho, 1909 to I9I9," is dealt with by Mr. J. A. Larsen, Forest Examiner, and $\mathrm{Mr}$. C. C. Delavan, Fireassistant. During the eleven years nearly 5,000,000 acres of land were burned over in this district, with a damage to standing timber estimated at 28 million dollars, and an outlay in fire prevention and suppression of about four and one-half million dollars. Diagrams are given showing for seven sections of the district the average area per fire for each of the eleven years and the mean for the whole period. The years $x 910$ and I9I9. stand out as experiencing the most disastrous fires. The outstanding causes of forest fires appear to be lightning, railroads, campers, and slash burning, of which lightning is the cause of the greatest number; some sections are said to have few fires from any cause except lightning. Sunshine, wind movement and moisture deficit are much above the average in years of bad forest fires, and there are other meteorological elements which afford very critical weather for forest fires. There is a general belief that forecasts of fire-weather conditions would be invaluable if they could be made sufficiently accurate and localised to be trustworthy.

"The Occurrence of Lightning Storms in Relation to Forest Fires in California" is dealt with in the Monthly Weather Review for April 1923, by Mr. S. B. Show and Mr. E. I. Kotok, Forest Examiners. It is asserted that lightning has been proved to be the principal single cause of forest fires in California and throughout the West. In the national forest of California during the years I9 I $\mathrm{I}-20$ lightning has been responsible for 4363 out of a total of 10,527 fires, or $4 \mathrm{I} \cdot 5$ per cent. Further study of the storms involving lightning is strongly advocated; 89 per cent. of the lightning fires occur in June, July, and August. Among the number of articles in the Monthly Weather Review for November 1923, Mr. H. H. Weidman of the U.S. Forest Service mentions that if the forester knows the different degrees of inflammability of the fuel in terms of differences in its moisture content, it is possible for him to state definitely for to-morrow or the next day what influence the approaching weather will have in making it wetter or drier.

The cause of thunderstorms is now better understood, and with our increased knowledge of the upper air, the knowledge of thunderstorms will be still further advanced and better warnings will be disseminated.

\section{An Analysis of the Jewish Race. ${ }^{1}$}

\section{By Dr. R. N. Salaman.}

THE Jewish communities of the world constitute no pure race, and in their features and physical characteristics represent no single uniform or even average type. An examination into the origins of the Jewish people offers an ample explanation of this diversity of appearance.

The Jewish people to-day are grouped into two stocks, the Ashkenazic and the Sephardic. The first comprises the Jews of Russia, Central Europe, Western Europe, and England; the latter is made up of the Spanish and Portuguese Jews and the Jews of Asia Minor, Egypt, and Arabia. Both groups derive directly from the common source in Palestine and Mesopotamia which, taking different paths in the diaspora, met with different fates. This paper deals with the Ashkenazic, partly because they are the more accessible, but chiefly because in the writer's view they have been far less subject to local intermarriage during their sojournings.

The origin and composition of the Jewish mass up to the first century of this era may be very briefly described as follows: The Abrahamic family were of a tribe, the Ibri, whom the Egyptians knew as Habiru. These were nomadic Semites equivalent to Bedouins. On their return to Palestine they met, conquered, and

1 Synopsis of a paper read before the Royal Anthropological Institute on April I5.

NO. 2844 , vOL. I I 3$]$ amalgamated with the Amorites and the Hittites. The monuments as well as philological evidences show that the former were Semites and in appearance not to be distinguished from the Habirus. The Hittites were a people the governing class of which at least were entirely different from both the Amorite and Hebrew and are to-day represented by the Armenians.

Later the Israelites, now a mixed race of Semite and Armenoid origin, took into their midst a third people, the Philistines, a typical Mediterranean race. The Semitic Amorite and Habiru were essentially tall, long-headed people with sloping narrow brow, long face, a long, straight, broad nose with large nostrils, big mouth and heavy, large lips. The characteristics of their facial features are length and heaviness. The Hittite was of medium height, thick build, roundheaded, often with a very high, flattened occiput. The features are characterised by their extreme roundness - a large, rounded, hooked, "Jewish" nose, the angles of the face and jaw likewise rounded, the mouth neither large nor the lips coarse.

The Philistines were represented on the walls of Karnak, as their progenitors were on the frescoes of Crete, as a small, delicately built people with long head, very refined clear-cut features, small nose often retroussé, small mouth and refined lips. A facial type characterised by the fine chiselling of the features, 